Gerión. Revista de Historia Antigua

ISSN: 0213-0181

https://dx.doi.org/10.5209/geri.74785

\title{
La presencia de sellos sobre ánforas Dressel 20 en Londinium- Camulodunum y Mogontiacum: un análisis cuantitativo-comparativo y sus dinámicas comerciales derivadas ${ }^{1}$
}

\author{
José Remesal Rodríguez²; Juan Manuel Bermúdez Lorenzo³
}

Recibido: 11 de diciembre de 2018 / Aceptado: 24 de marzo de 2020

Resumen: El presente estudio pretende comparar el material epigráfico sobre ánforas tipo Dressel 20 (sellos) de dos puntos del Imperio Romano: Mogontiacum (Mainz) y Londinium (Londres) junto a Camulodunum. Para ello se tendrá en cuenta la información contenida en la base de datos de epigrafía anfórica CEIPAC. Tiene como objetivo delimitar las dinámicas de importación del aceite de oliva desde la Bética y ponerlo en relación con el consumo militar o civil de las poblaciones correspondientes.

Palabras clave: sellos anfóricos; Dressel 20; historia comercial del limes.

\section{[en] The Presence of Seals on Dressel 20 Amphorae in Londinium- Camulodunum and Mogontiacum: a Quantitative-comparative Analysis and its Derived Trade Dynamics}

\begin{abstract}
This paper aims to compare the epigraphy on amphorae Dressel 20 (stamps) of two points of the Roman Empire with a parallel chronology: Mogontiacum (Mainz) and Londinium (London), with Camulodunum. For this purpose, we will take in account the information contained in the database CEIPAC of amphorae epigraphy. We have as objective to delimit the dynamics of oil arrival from Baetica and put it in relation with the army or civil consumption of these towns.

Keywords: Amphorae Stamps; Dressel 20; Trade History of the Limes.
\end{abstract}

Sumario: 1. Introducción. 2. Contextos de los lugares de hallazgo elegidos. 3. Análisis de la muestra. 4. Conclusiones. 5. Anexo. 6. Referencias bibliográficas.

Cómo citar: Remesal Rodríguez, J.; Bermúdez Lorenzo, J. M. (2021): La presencia de sellos sobre ánforas Dressel 20 en Londinium-Camulodunum y Mogontiacum: un análisis cuantitativo-comparativo y sus dinámicas comerciales derivadas, en Gerión 39/1, 125-147.

\footnotetext{
Proyecto EPNet de la ERC 2013 AdG 340828. Proyecto del MICINN HAR2017-85635-P.

2 Universidad de Barcelona.

E-mail: remesal@ub.edu

ORCID: 0000-0003-1474-3123

3 Universidad Rey Juan Carlos.

E-mail: juan.bermudez@urjc.es

ORCID: 0000-0002-7291-1079
} 


\section{Introducción}

Ante la discusión sobre primitivismo o modernismo de la economía romana hemos defendido que es preciso realizar estudios de carácter microanalítico, desde los que, posteriormente, podamos hacer un análisis general de la economía romana. Desde el grupo CEIPAC hemos centrado nuestra investigación en el análisis de la producción y comercio de alimentos durante el Imperio romano. Para ello estudiamos las ánforas en que se distribuyeron algunos alimentos, sobre todo, aceite de oliva, vino y conservas de pescado, cuyos restos podemos encontrar a lo largo y ancho del espacio ocupado por Roma. Hasta tiempos recientes, por ejemplo, en el limes germano, en las memorias de excavación e inventarios de museos sólo se hacía constar la presencia o ausencia de las ánforas, sin que se realizaran estudios estadísticos que permitiesen comparar el volumen de importación de uno u otro tipo de ánforas. De igual modo, y más concretamente, los epígrafes quedaban en el olvido. Los trabajos realizados tanto en el limes como en Roma y en las provincias han hecho que la disciplina se haya desarrollado de una forma notoria, especialmente desde mediados del s. XX.

Nuestro caso de estudio es la producción y comercio del aceite bético, contenido en las ánforas definidas como tipo Dressel 20. Este tipo se produjo a lo largo de casi tres siglos en una zona bien delimitada: el valle del río Guadalquivir (Baetis), entre Hispalis (Sevilla) y Corduba (Córdoba), y el de su afluente el Genil (Singilis), entre la ciudad de Astigi (Écija) y su confluencia con el Guadalquivir (Fig. 1).

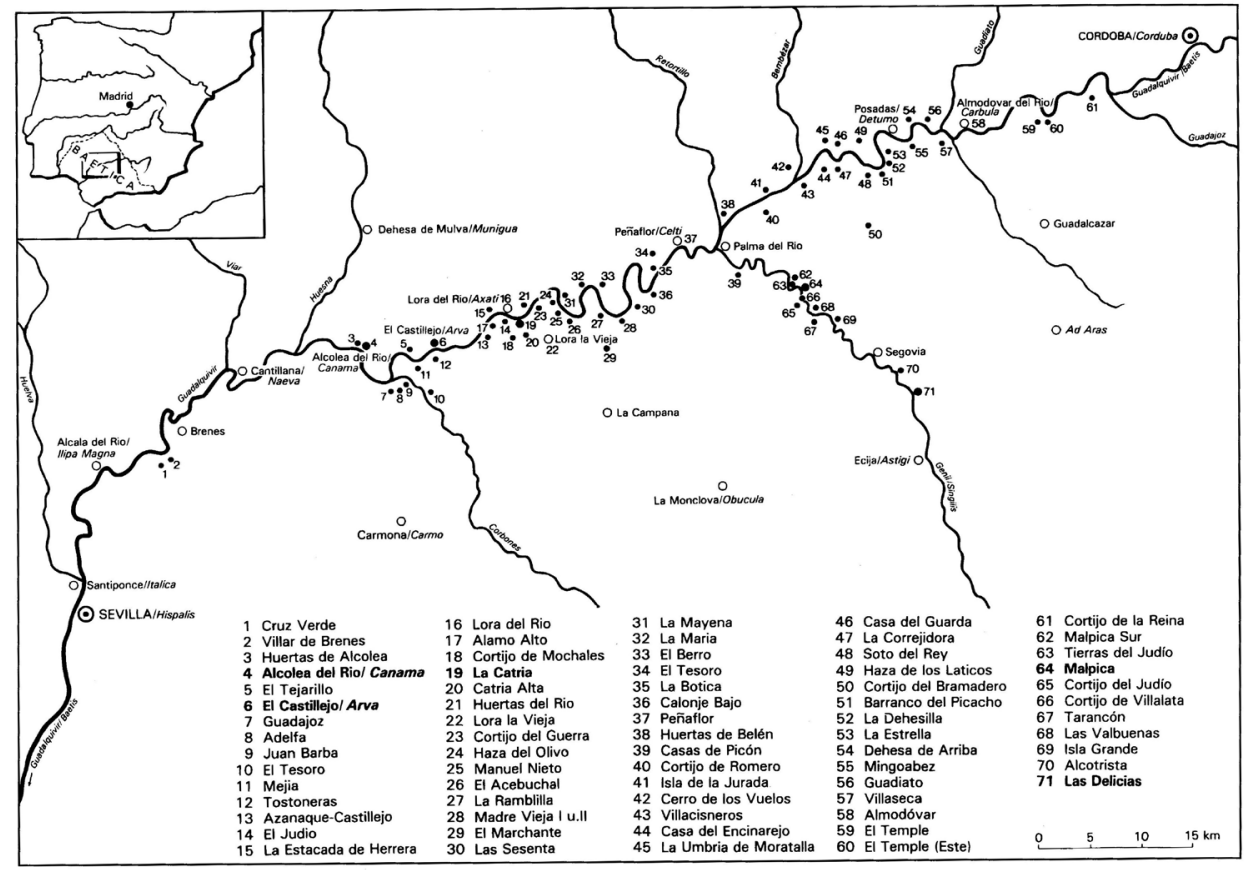

Fig. 1. Lugares de producción en la Bética (Remesal 1997, Abb. 2)

4 De no señalarse lo contrario, todas las tablas y figuras de este trabajo son de elaboración propia. 
Como hemos señalado reiteradamente, una serie de circunstancias facilitan nuestro estudio: ${ }^{5}$

- Son las ánforas más difundidas en todo el occidente mediterráneo.

- Están frecuentemente selladas.

- Conocemos relativamente bien su área de producción, que se centra alrededor de los ríos Guadalquivir y Genil.

- Disponemos en Roma del conocido Monte Testaccio, una colina artificial compuesta exclusivamente por los restos de ánforas olearias, de las que, aproximadamente, el $85 \%$ son ánforas de nuestro tipo Dressel 20. Estas características se ven hoy día reforzadas por dos hechos: primero, por la creación - desde la década de los noventa- de la base de datos de epigrafía anfórica del CEIPAC, ${ }^{6}$ en la que se recogen miles de los sellos impresos sobre estas ánforas en todo el espacio europeo y, segundo, por las modernas excavaciones en el Monte Testaccio. ${ }^{7}$

Mientras que, en general, sólo disponemos de los sellos impresos antes de la cocción del ánfora a lo largo y ancho de todo el Imperio, en el Testaccio se han conservado también los llamados tituli picti, las "etiquetas", que, escritas con tinta negra sobre el ánfora, indican una serie de datos que $\mathrm{H}$. Dressel definió como alfa: la tara del ánfora; beta: los dueños del aceite; gamma: el peso neto del aceite contenido; estas tres inscripciones se escribieron verticalmente a partir del cuello del ánfora. A la derecha de ellas se escribió el titulus delta, una $R$ barrada, que significa $R$ (ecensitum) o $R$ (ecognitum), controlado; el distrito fiscal desde el que se realizó el control: Hispalis, Corduba y Astigi, capitales de tres de los cuatro conventus iuridici en que se dividía la Bética; la repetición del peso gamma; el nombre de los personajes intervinientes en dicho control y la datación consular. Adicionalmente, fragmentos de tituli picti en rojo, referidos seguramente a condiciones de almacenaje, se suelen conservar también sobre ánforas Dressel 20.

Aquí, como encuadramiento geográfico de nuestro caso de estudio, analizaremos los sellos llegados a dos lugares significativos de dos provincias distintas: Londinium (Londres), en Britannia, y Mogontiacum (Mainz), en Germania Superior. Los motivos para la elección de dichas ciudades son dos: se trata de lugares que se cree albergaron un número de habitantes similar, pero que se diferencian entre sí porque Londinium tuvo una población eminentemente civil, mientras que Mainz tuvo una población militar. Las cronologías de ambas ciudades difieren en varias décadas. Para compensar el espectro cronológico y conseguir que los materiales resulten comparativos hemos sumado los materiales de Camulodunum (actual Colchester) a los de Londinium. ${ }^{8}$ Así podemos disponer de la misma horquilla cronológica que en Mogontiacum. En total contamos con 320 ejemplares en Londinium, 165 en Camulodunum y de 404 en Mainz, volumen semejante al que se encuentra en otros lugares del Imperio, como Augst o Lyon.

Son especialmente útiles para el estudio general de la producción y distribución de este tipo de ánforas los siguientes corpora: Bonsor 1931; Ponsich 1974; 1979; 1987; 1991; Remesal 1986 y 1997; Martin-Kilcher 1987; Ehmig 2003, 2007.

http://ceipac.ub.edu Trabajo realizado gracias al proyecto ERC 2013 ADG 340828 y HAR 2017-85635P.

Blázquez et alii 1994; Blázquez - Remesal 1999; 2001; 2003; 2007; 2010 y 2014.

Por ello, al referirnos a Londres en este artículo, quedará implícito que hablamos de los materiales de Londinium у Camulodunum. 


\section{Contextos de los lugares de hallazgo elegidos}

El territorio de Mogontiacum $^{9}$ se conquistó en época de Augusto, en plena expansión por Germania. Druso hizo construir un campamento legionario permanente a orillas del Rin hacia el 13/12 a.C., en el territorio que luego sería Mainz. Desde el año 42 y hasta el año 90 hubo dos legiones establecidas en el lugar, cuyo asentamiento se situó en el actual barrio de Universitätsklinik y Kästrich. En torno al asentamiento de personal militar surgió un asentamiento civil que, después de la revuelta de Lucio Antonio Saturnino, recibió el estatus de municipium y se convirtió en capital de Germania Superior, a la vez que se redujo el número de legiones a una. ${ }^{10}$ Su posición convirtió a Mogontiacum en un importante foco geoestratégico, que aseguraba el control en torno al área media del río Rin.

Haensch defiende que Mogontiacum nunca tuvo un papel urbano, sino más bien el de campo militar junto a una población sin aparente organización centralizada. ${ }^{11}$ Sea como fuere, la presencia de una legión asegura una población mínima de 6000 personas, dato que debemos tener en cuenta para posteriores análisis. Las ánforas halladas en Mainz han sido estudiadas por varios investigadores. Callender, ${ }^{12}$ Remesal $^{13}$ y Ehmig ${ }^{14}$ han recogido la totalidad de la epigrafía anfórica del lugar conocida hasta ahora.

Camulodunon ${ }^{15}$ había sido un centro prerromano y capital de la tribu celta de los trinovantes. ${ }^{16}$ Se sitúa geográficamente entre Venta Icenorum y Londinium. ${ }^{17}$ En época de Claudio se creó en su emplazamiento la Colonia Claudia Victricensis, donde se apostó la legio XX Valeria Victrix ${ }^{18}$ y se situó la sede del gobierno provincial; no obstante, después de la revuelta de Boudica dicha sede se trasladó a Londinium. Debemos, por tanto, tener en cuenta una población militar mínima de 6.000 habitantes en Camulodunum. La epigrafía anfórica de Colchester ha sido recogida principalmente por Callender ${ }^{19}$ y por Carreras y Funari. ${ }^{20}$

Londinium se sitúa a orillas del río Támesis. Existen dos hipótesis sobre el origen de Londres: la primera plantea que creciera como castellum en época de Claudio, en torno al cual se desarrollaría también un vicus $;{ }^{21}$ la segunda defiende que se fundara en la misma época una ciudad de nueva creación como colonia. ${ }^{22}$ El lugar se caracteriza por ser encrucijada de varias calzadas a orillas del Támesis. Como Camulodunum,

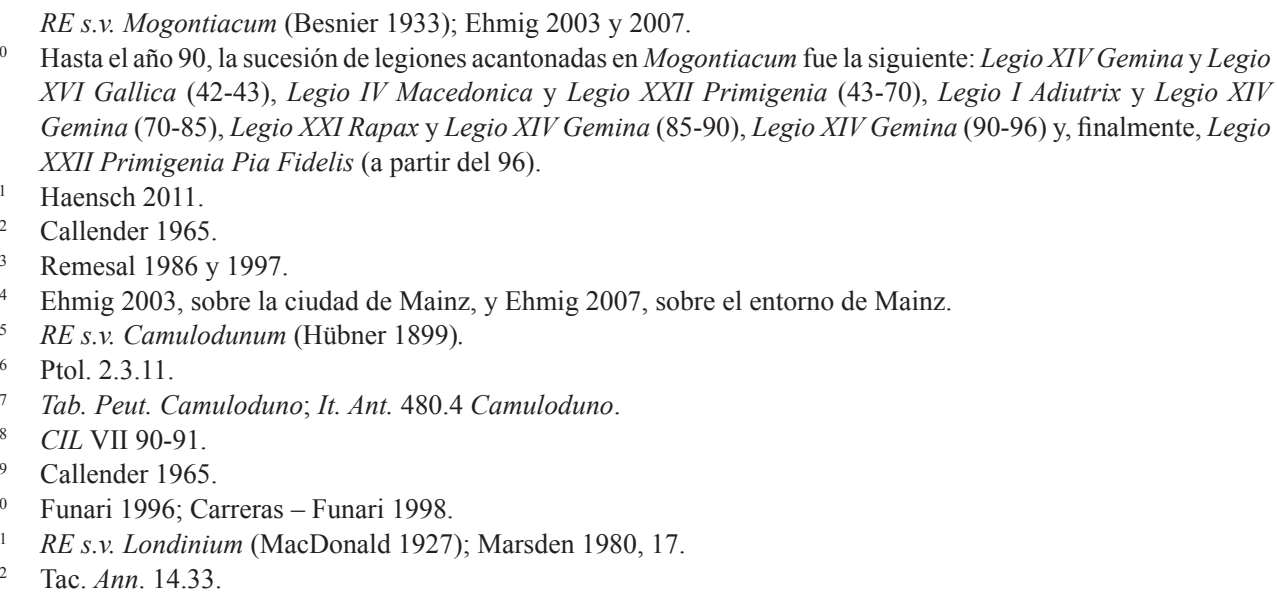


también fue destruida durante la revuelta de Boudica. ${ }^{23}$ Su protagonismo provincial se fortalece cuando Camulodunum pierde el estatus de capital provincial en su favor. Londres tiene, como hemos dicho, una población civil ${ }^{24}$ de unas 30.000 personas, según las estimaciones de Frère. ${ }^{25}$ Las principales obras que recogen la epigrafía anfórica de Londres son el CIL VII,${ }^{26}$ Callender ${ }^{27}$ y Carreras y Funari. ${ }^{28}$

Partimos de la idea de que el aceite de oliva es un producto exótico en ambas regiones y que su introducción debió de producirse por un factor externo determinante: la presencia del ejército romano en ambas provincias. Defendemos que ya desde Augusto existió un sistema de abastecimiento (praefectura annonae) del ejército organizado desde Roma, que utilizaba los recursos de las provincias mediterráneas, pagados en natura, para abastecer tanto a Roma (annona Urbis) como al ejército (annona militaris). ${ }^{29}$ Por otra parte, el aceite de oliva, necesario para comer a la romana, bañarse a la romana o iluminarse a la romana, se convirtió en un producto de prestigio para sociedades que pretendían asemejarse a los conquistadores. De aquí surgen dos cuestiones generales ulteriores a nuestro estudio: hasta qué punto el estado romano intervino en la economía y hasta qué punto condicionó dicha intervención las relaciones entre las diversas provincias del Imperio, lo que hemos definido como interdependencia provincial. ${ }^{30}$

Por otra parte, se plantea la cuestión de la ruta que se siguió para abastecer a estas provincias. La visión tradicional consideraba que la única ruta era el valle del Ródano, de allí al valle del Rin y desde la desembocadura del Rin a Britannia. ${ }^{31}$ Ya en 1986 defendimos que estas provincias se abastecieron a través del Atlántico, ${ }^{32}$ mediante una navegación que se basaría en gran parte en el cabotaje, y que enlazaría con el Rin, o sea, el sentido contrario al que proponían los investigadores que se inclinaban por el abastecimiento por el Ródano. Recientemente, un estudio realizado dentro del proyecto EPNet propone que los sellos llegados a Britannia y Germania son más semejantes entre sí, que entre éstos y los llegados a la Gallia Lugdunensis, ${ }^{33}$ lo que vendría a confirmar que ambas provincias se abastecieron a través de la ruta atlántica.

A la hora de abordar el estudio de los sellos en ánforas, debemos tener en cuenta los límites a los que nos enfrentamos; dos son las cuestiones previas a considerar: qué significan los sellos y qué proporción de ánforas se sellaban.

\footnotetext{
Marsden 1980, 31.

24 Aunque conocemos algunos militares que sirvieron en la officina del gobernador. Merrifield 1983, 77. Véanse las siguientes inscripciones sobre personal militar subalterno: RIB III, 2005 (beneficiarius); CIL VII $24=$ RIB I, 19 (speculator). Marsden 1980, 19.

25 Frère 1987, 253: "Tacitus assesses the total casualties at London, Verulamium and Colchester during the Boudiccan sack at 70,000, and his language supports a population for Colchester and even Verulamium of about 15,000 each, and perhaps one as large as 30,000 for London”. Véase Tac. Hist. 14.33.

26 Hübner 1873.

27 Callender 1965.

28 Carreras - Funari 1998.

29 Remesal 1986; 1997 y 2011.

30 Remesal 2008.

31 Esta ruta ha sido defendida frecuentemente por los autores galos: Rougé 1966; Tchernia 2011.

32 Remesal 1986; 1997; 2010 y 2011. La obra más reciente sobre este tema se puede ver en Schäfer 2017, donde se incluyen las últimas técnicas de análisis de contabilización de tiempos necesarios y comparados entre las diferentes rutas contrapuestas.

33 Rubio et alii 2017.
} 
Sobre el significado de los sellos hay dos interpretaciones tradicionales, sintetizadas recientemente por Berni: ${ }^{34}$ por una parte, la defendida por los que consideran que estos sellos representan a los alfareros o a los gestores de las alfarerías y, por otra, la mantenida por quienes consideran que representan al dueño del aceite contenido en el ánfora en el momento del envasado. ${ }^{35}$ La mayoría de los sellos en ánfora Dressel 20 se componen, de una manera más o menos abreviada, de unos tria nomina, a los que frecuentemente se añade el nombre de la figlina donde se produjo el ánfora y otros nombres, señalados por un cognomen, en los que se representa, en nuestra opinión, a los gestores de la figlina o a los figuli que realizaban el ánfora. Esta información puede aparecer toda en un único sello o en varios. En época flaviotrajanea es frecuente hallar en una de las asas impreso un sello con tria nomina y en la otra un cognomen. En el s. III es usual hallar tres sellos sobre un ánfora: el primero, con unos tria nomina, en una de las asas; el segundo, que indica la figlina, en la otra; el tercero, en el vientre, con un cognomen $+f$ (ecit) of (igulus). De un mismo sello pueden darse gran número de variantes: tamaño, diversidad de tipo de letras, puntuaciones, un mayor o menor desarrollo del nombre escrito... ${ }^{36}$

Cuántas ánforas se sellaban es algo que sólo podemos determinar si disponemos de conjuntos numerosos, como puede ser el hallazgo de un almacén o el de una nave hundida. En nuestro caso disponemos del material del Testaccio, lugar a donde llegaron las ánforas enteras y donde fueron fragmentadas, sin que exista tierra entre ellas. Podemos dividir el peso total del material hallado en nuestros sondeos y a su vez dividirlo por el peso estándar de una de nuestras ánforas Dressel 20: 30 kilogramos. El resultado es el siguiente (Fig. 2), diversificados los datos por campañas de excavación:

\begin{tabular}{|l|l|l|l|l|l|l|l|}
\hline campaña & \multicolumn{1}{|c|}{ siglo } & $\begin{array}{c}\text { peso } \\
\text { extraído }\end{array}$ & \multicolumn{1}{|c|}{$\mathbf{m 3}$} & peso/m3 & $\begin{array}{c}\mathbf{n}^{\mathbf{0}} \\
\text { ánforas }\end{array}$ & $\mathbf{n}^{\mathbf{0}}$ sellos & frecuencia \\
\hline 1989 & s. II & 3783,00 & 5,70 & 663,68 & 126,10 & 80 & 0,63 \\
\hline 1989 & s. III & 3696,00 & 6,20 & 596,13 & 123,20 & 184 & 1,49 \\
\hline 1990 & s. II & 10176,49 & 12,00 & 848,04 & 339,22 & 73 & 0,22 \\
\hline 1991 & s. III & 9148,50 & 5,40 & 1694,17 & 304,95 & 322 & 1,06 \\
\hline 1992 & s. II & 3953,00 & 5,20 & 760,19 & 131,77 & 98 & 0,74 \\
\hline 1993 & s. II & 10205,80 & 9,20 & 1109,33 & 340,19 & 113 & 0,33 \\
\hline 1994 & s. II & 6609,90 & 9,30 & 710,74 & 220,33 & 73 & 0,33 \\
\hline $1995-6-7$ & s. III & 15939,90 & 29,2 & 545,89 & 531,33 & 254 & 0,48 \\
\hline $1998-9$ & s. III & 15025,00 & 22,80 & 658,99 & 500,83 & 325 & 0,65 \\
\hline 2000 & s. III & 9409,00 & 10,80 & 871,20 & 313,63 & 114 & 0,36 \\
\hline 2005 & s. III & 12352,50 & 14,40 & 857,81 & 411,75 & 155 & 0,38 \\
\hline
\end{tabular}

Berni 2008, 23.

Remesal 1977-1978, 91; también la recogen Manacorda - Panella 1993, 55.

El estado de la cuestión en Barea Bautista et alii 2008; Berni 2008; Remesal 2011 y 2016. 


\begin{tabular}{|l|c|l|l|l|}
\hline & peso & $\mathbf{n}^{\mathbf{0}}$ ánforas & $\mathbf{n}^{\mathbf{0}}$ sellos & frecuencia \\
\hline material siglo II & 34728,19 & 1157,61 & 691,00 & 0,60 \\
\hline material siglo III & 65570,90 & 2185,70 & 1100,00 & 0,50 \\
\hline
\end{tabular}

Fig. 2. Pesos de los materiales y frecuencias de los sellos encontrados en el Monte Testaccio

Otra cuestión definitoria es la de la cronología de nuestros materiales. Los criterios de datación usados en este sentido son:

- Uso de la tipología como elemento cronológico. Conocemos a grandes rasgos la evolución tipológica de las ánforas Dressel $20 .^{37}$

- Uso de las dataciones ofrecidas por los lugares de hallazgo. En este caso hay que contrastar la datación tipológica con la datación del contexto en que aparezca, pues la deposición puede tener una datación diversa a la tipológica; en este caso preferimos la datación tipológica, pues el material puede hallarse en un nivel de deposición más tardío. Por otra parte, el material tiene valor económico en el momento en que llega al sitio, no por sus posteriores usos.

- Datación Testaccio: hablamos de "datación absoluta" cuando un sello ha sido hallado en el mismo fragmento en el que existe un titulus pictus delta con una datación consular determinada. En el caso en que tengamos dataciones diversas señalamos las fechas concretas, por ejemplo 149-161, ya que, aunque no sepamos el inicio y fin de la producción, podemos ofrecer al menos un periodo seguro en el que se produjo. Hablamos de "datación contextual" cuando, no teniendo una datación absoluta, atribuimos al sello la datación del contexto en que aparece en el Testaccio.

Conocemos el lugar concreto de producción de muchos de estos sellos en la Bética, pero al no disponer de tituli picti en los lugares de recepción desconocemos los vectores, los comerciantes que acarrearon los productos hasta esos lugares.

Una última cuestión sería determinar el valor estadístico de nuestra muestra. En otro trabajo hemos puesto de manifiesto ${ }^{38}$ que una muestra con el volumen de documentos aquí recogidos puede considerarse válida y que su aumento indicará la misma tendencia, aunque, naturalmente, la aportación de más documentos modificará algunos de sus aspectos.

El estudio cuantificado de las ánforas no se ha llevado a cabo de forma sistemática y continua, por ello, no disponemos de datos seriados para una gran parte de los conjuntos anfóricos. Para los lugares de los que sí disponemos de dichos datos, son paradigmáticas las obras de Martin-Kilcher, ${ }^{39}$ sobre Augst y Kaiseraugst, Ehmig, ${ }^{40}$ sobre Mainz, o Schimmer, ${ }^{41}$ sobre Kempten, en las que sí han tenido en cuenta estos datos cuantificables. Últimamente los autores que han estudiado materiales con esta metodología son Panella y Rizzo, ${ }^{42}$ sobre las ánforas de Ostia;

\footnotetext{
Martin-Kilcher 1983; Berni 2008 y 2017.

Remesal 2017.

Martin-Kilcher 1987.

Ehmig 2003 y 2007.

Schimmer 2009.

Panella - Rizzo 2014.
} 
Laubenheimer y Marlière, ${ }^{43}$ sobre las del noroeste de la Galia; y Carreras,${ }^{44}$ entre otros, sobre las de Nimega. También sobre Hispania Ulterior debemos destacar el trabajo de Mateo. ${ }^{45}$

\section{Análisis de la muestra}

Los materiales que analizamos tienen un origen que se encuadra dentro de los conventus iuridici de la Bética; entendemos que estos conventus tenían también una función fiscal. ${ }^{46}$ En el conventus de Hispalis, que en la orilla derecha del río Guadalquivir llegaba hasta Celti (municipium flavium Celtitanum, Peñaflor, Sevilla), es en el que existe mayor densidad de ciudades con centros de producción de ánforas documentados, convertidas en municipios de derecho latino en época Flavia. En el conventus Cordubensis, además de la propia la capital, Corduba, sólo conocemos dos municipios con tales centros: Carbula y Detumo. Por su parte, en el conventus Astigitanus -que se correspondía con todo el espacio comprendido entre Astigi y la desembocadura del Singilis en el Baetis- conocemos centros productores en las ciudades de Segovia,${ }^{47}$ en la orilla derecha, y Segida Augurina, en la izquierda. ${ }^{48}$

La mayor parte del material, tanto en Londinium-Camulodunum como en Mogontiacum, procede del conventus Hispalensis, representado de forma igual en ambas; sin embargo, el material del conventus de Astigi hallado en Mogontiacum duplica al hallado en Londinium-Camulodunum; finalmente, el material del conventus Cordubensis está representado de forma parecida en ambas zonas (Fig. 3). Es interesante señalar que el material sea proporcionalmente el doble en Mainz que en Londres. Si comparamos la proporción obtenida en nuestro caso de estudio con el conjunto de los materiales hallados en toda Britannia y toda Germania Superior (Fig. 4), y tenemos en cuenta la diferencia del volumen de una y otra muestra, podemos inferir que la proporción de la representatividad de los conventus es semejante en una y otra provincia. (Fig. 5).

Pasemos al estudio de los materiales procedentes de cada conventus (Fig. 6-7).

En el conventus Hispalensis el lugar emisor más destacado es "La Catria" (Lora del Río, Sevilla), que es el centro de producción de mayor tamaño conocido en la Bética. La mayoría de sus sellos corresponden a tria nomina, a los que se añade el término Portus. ${ }^{49}$ Esta característica nos ha llevado a proponer que se trate de una figlina ubicada en terreno público. ${ }^{50}$ Aunque en su día atribuimos este lugar al territorium de Axati (Lora del Río, Sevilla), pensamos hoy que habría que vincularlo al territorio de la ciudad ubicada en el lugar llamado "Mesa de Lora", ${ }^{51}$ que tal vez se corresponda con la antigua ciudad de Oducia. ${ }^{52}$ El sello

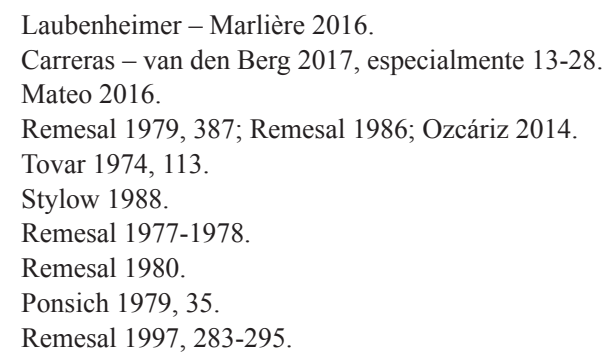


PORODV fue leído ya por Dressel ${ }^{53}$ como POR(tus) ODV(ciensis). En época de Severo se producen en este lugar los sellos PORTO y POPVLI e incluso $P O T O P O P V L I$, frecuentes en El Testaccio, ${ }^{54}$ pero que se encuentran escasamente en las provincias.

Aunque el número de ánforas procedentes del conventus Hispalensis es el más elevado, tanto en Londinium-Camulodunum (28 ejemplares) como en Mogontiacum (25 ejemplares), en la mayoría de los casos los sellos sólo están representados por un ejemplar. Algunos sólo están presentes en uno de los polos de estudio: CEFP; LCM; PORPS; PQAF en Mainz; PORCPR en Londres. Algunos de ellos están proporcionalmente más representados en un lugar que en otro (Figs. 8-12). La mayoría de estos sellos son datables en época flaviotrajanea y a mediados del s. II. El sello PARVA, de Arva, se data en el s. III.

Dos son los lugares mejor representados del conventus Astigitanus. El primero es el conocido como "Malpica" (Palma del Río, Córdoba) ${ }^{55}$ cuya presencia está bien atestiguada a mediados del siglo II. La característica es que sólo está representado por individuos de una misma familia de nomen Iuventius, particularmente por el personaje llamado C(aius) I(uventius) Al(binus), nombre que permiten desarrollar con seguridad algunos ejemplares. Existe en Axati una inscripción referida a un personaje de este nombre, ${ }^{56}$ que puede datarse en la misma época; no podemos asegurar que el personaje de los sellos y el de la inscripción sean el mismo individuo, aunque sería probable. También disponemos de un titulus pictus beta relacionado con este personaje. ${ }^{57}$ Esta familia está mejor representada en Mainz que en Londres (Fig. 12).

El segundo lugar se conoce como "Las Delicias" (Écija, Sevilla) ${ }^{58}$ y está representado en dos momentos cronológicos diversos, en época julio-claudia y a principios del s. III; a este último momento corresponden los sellos de la familia de los Iunii Melissi. Proporcionalmente están mejor representados en Mainz que en Londres, particularmente en época severiana, cuando el número de ejemplares hallados en Mainz duplica el número de los hallados en Londres (Fig. 8). De época julioclaudia destacan los sellos SVAVI y PSAVITI, que provienen de este mismo centro, y han sido hallados recientemente por el equipo de Mauné. ${ }^{59}$

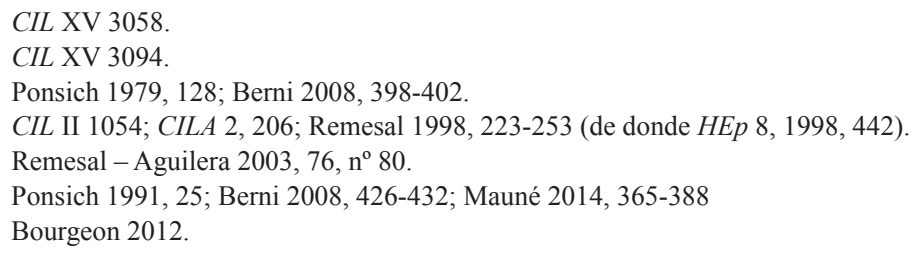



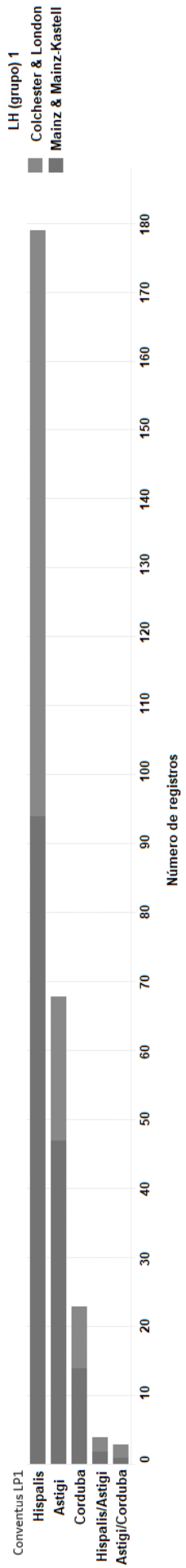

Fig. 3. Conventus de origen de los sellos encontrados en Colchester-Londres y Mainz 


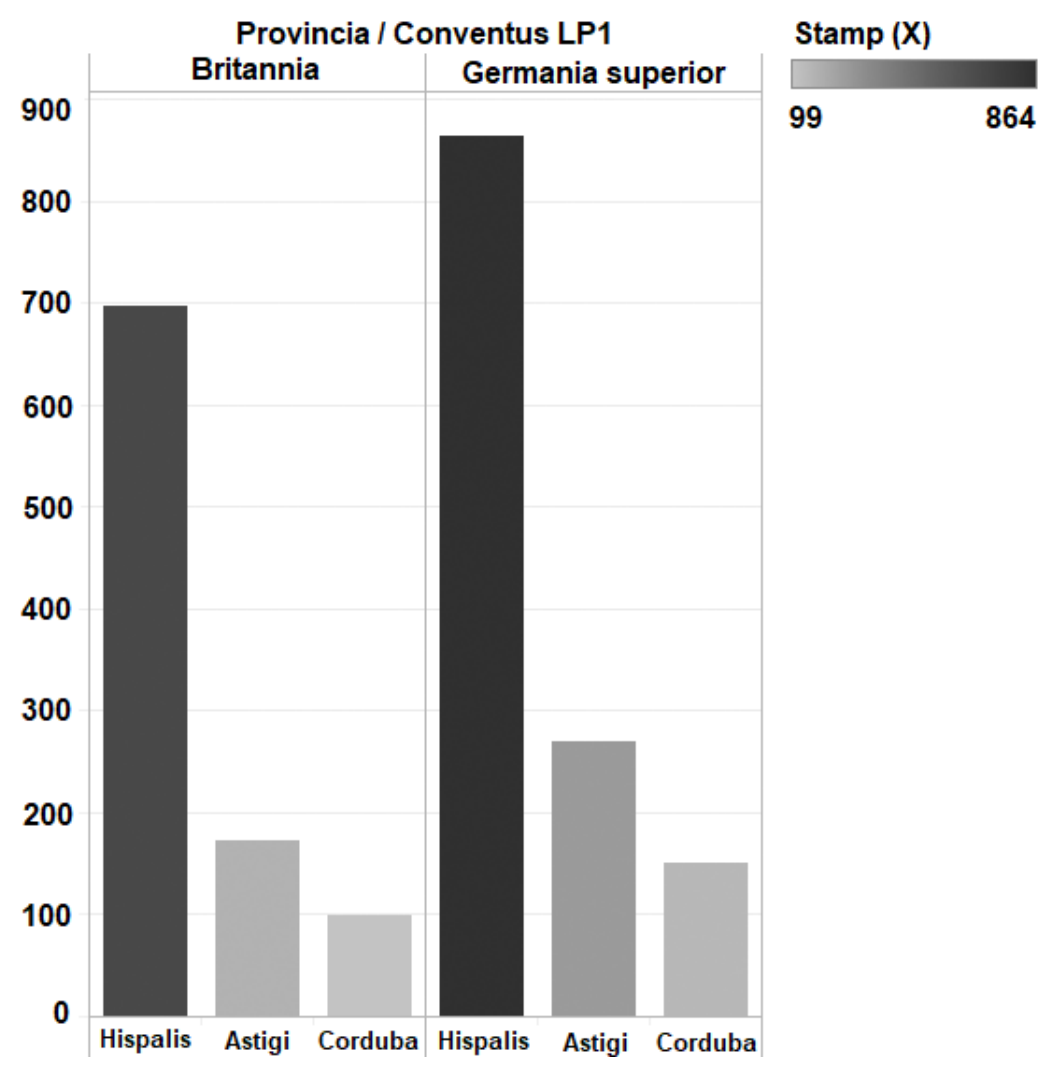

Fig. 4. Presencia de sellos por conventus en Britannia y Germania Superior

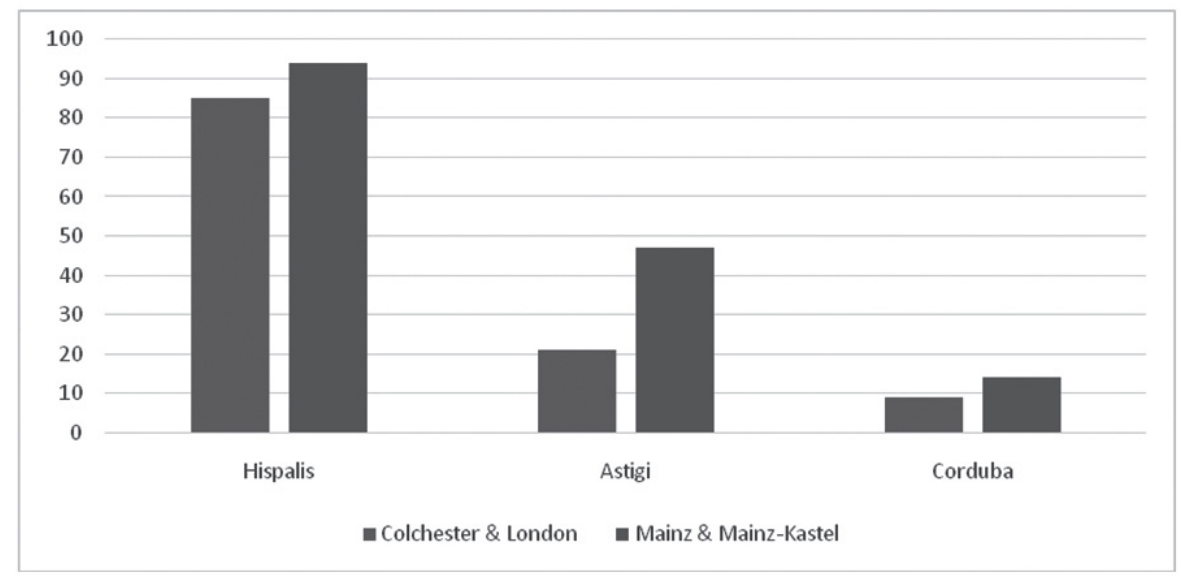

Fig. 5. Presencia de sellos por conventus en los dos polos de estudio 

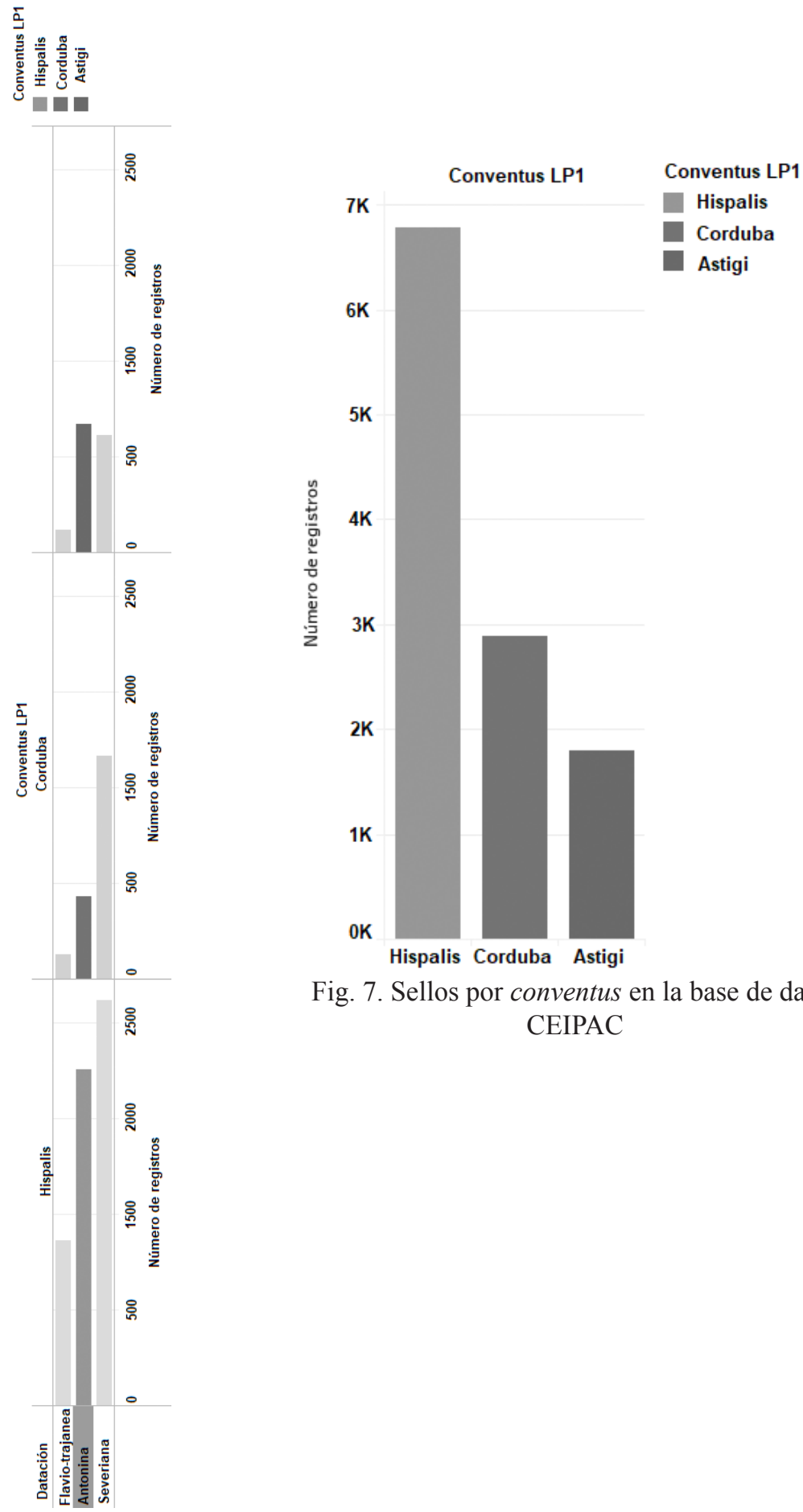

Fig. 7. Sellos por conventus en la base de datos CEIPAC

Fig. 6. Cronología de los sellos en la base de datos CEIPAC según conventus 


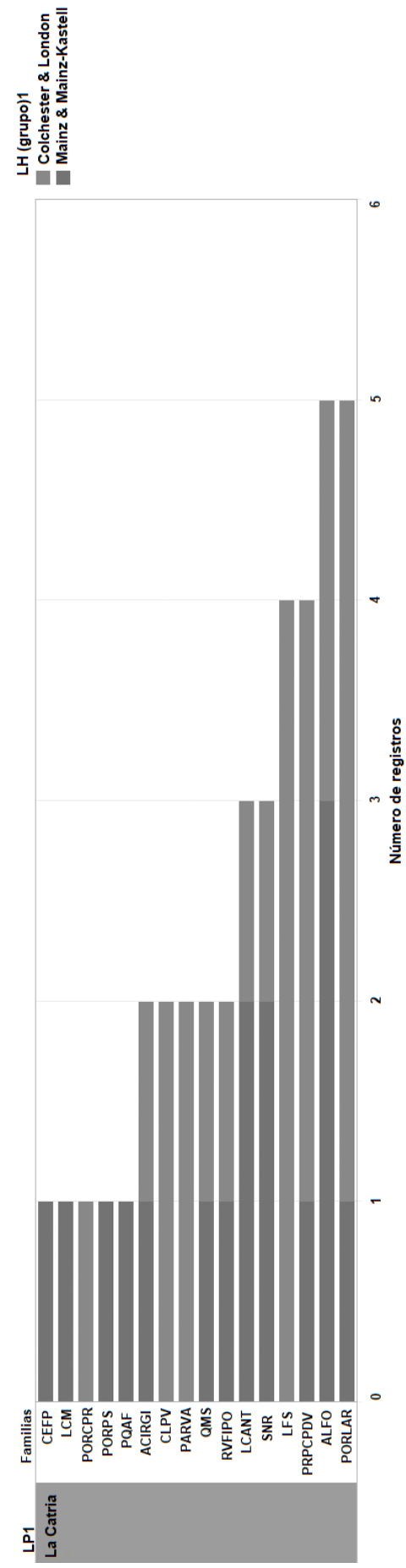

Fig. 8. Presencia de sellos provenientes de "La Catria"

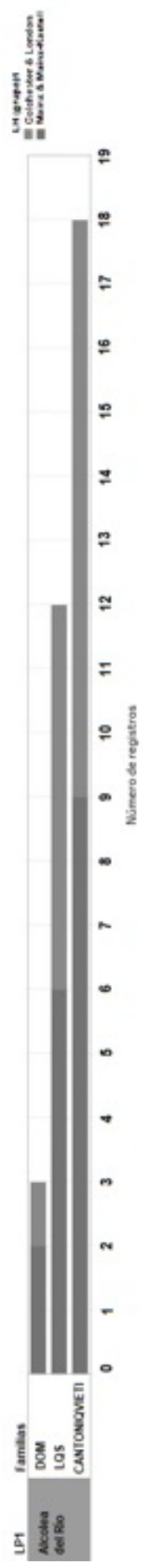

Fig. 9. Presencia de sellos provenientes de Alcolea del Río 


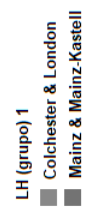

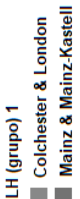
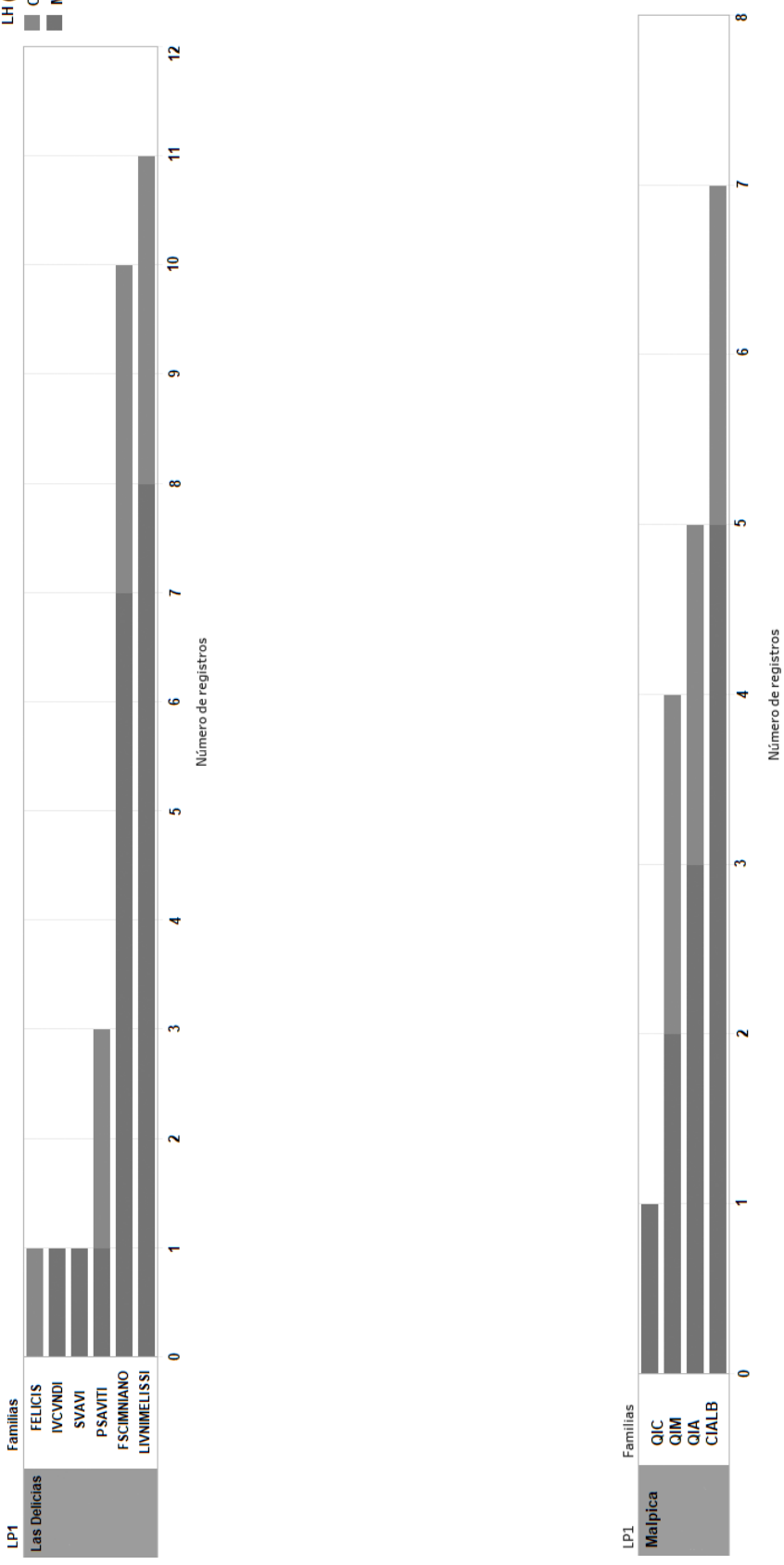

Fig. 10. Presencia de sellos provenientes de Fig. 11. Presencia de sellos provenientes de "Las Delicias" 

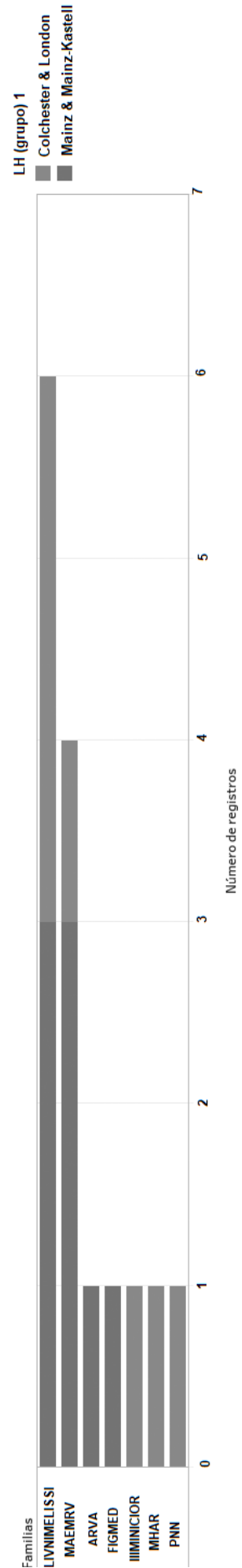

Fig. 12.- Presencia de sellos provenientes de la zona de Arva 
La muestra ofrece datos similares en los dos polos analizados, tanto en lo relativo a las procedencias (conventus y lugares de producción) como en lo que respecta a las cronologías. Estos datos reproducen las tendencias que se dan para sus respectivas provincias, con la salvedad que hemos apuntado de que, por lo general (según los datos de la base CEIPAC), los sellos provenientes del conventus Cordubensis tienen más difusión que los del Astigitanus, mientras en el caso de Londres y Mainz esto no se da: el número de sellos del conventus de Astigi en estos dos lugares es considerablemente superior. Con los datos tratados podemos afirmar que el material es coincidente entre los dos polos casi en su totalidad, por lo que inferimos algún tipo de vinculación en la llegada de las ánforas a un lugar y otro, vinculación que creemos debe relacionarse con el hecho de que el abastecimiento se realizó, en ambos casos, a través de la ruta atlántica. ${ }^{60}$

Carreras y Funari ya mostraron que los datos estadísticos de las provincias de Britannia y Germania son homologables, ${ }^{61}$ tendencia que vemos también reflejada en nuestros datos. La mayoría de los sellos de nuestros polos de estudio, recogidos en la base de datos CEIPAC, provienen del conventus de Hispalis. En segundo lugar, provienen del de Corduba y en tercer lugar del de Astigi. La suma de los sellos de los conventus de Corduba y Astigi no llega a igualar a la del de Hispalis.

En cuanto a las cronologías por conventus (Fig.6), se observa que la cantidad de sellos provenientes del Hispalensis se ve incrementada de forma destacada entre épocas flaviotrajanea, antonina y severiana, pasando de mil a dos mil sellos. Respecto al conventus de Corduba, el momento de mayor esplendor se da en época severiana, llegando a superar el millar de inscripciones. Las tendencias difieren cuando se analiza el material de Mainz y Londres en relación con sus provincias, Britannia y Germania Superior, pues aunque en las dos es el de Hispalis el conventus con mejor representación, el de Astigi supera al de Corduba en ambas.

Remesal calculó las necesidades de aceite alimentario anuales por militar en 12 litros, en período de paz. Teniendo en cuenta ese consumo medio, así como la población mínima estimable por la presencia militar (unos 6.000 hombres en el caso de la legión de Mainz), un cálculo sencillo arroja un total de 72.000 litros. Con esa cifra, dividida entre la cantidad de litros que lleva un ánfora Dressel 20, unos 70 litros por objeto, llegamos a la conclusión de que a Mainz debieron de llegar en un año un total aproximado de 1.028 ánforas, como mínimo, para abastecer a esa legión. Estas 1.028 ánforas suponen un peso total de unas 100 toneladas; es decir, una legión necesitaría 100 toneladas. En un barco de grandes dimensiones, con una capacidad de carga de hasta 500 toneladas, ${ }^{62}$ podría transportarse la totalidad de las necesidades mínimas para la tropa apostada en Mogontiacum.

El número de ánforas necesarias para la ciudad de Londinium es, a priori, muy superior, pues, si aceptamos que llegó a tener 30.000 habitantes, podríamos deducir, siguiendo los cálculos ya citados, una cifra de 5.000 ánforas Dressel 20. Esto supone un peso de unas 500 toneladas. No obstante, entendemos que este cálculo no ofrece una cantidad real de lo que supondrían las verdaderas necesidades de Londinium,

60 Remesal 1986 y 2010. Véase también Rubio et alii 2018.

${ }^{61}$ Carreras - Funari 1998, 21: "Se observa que la región bética de La Catria era la principal zona exportadora bética seguida de Las Delicias y Arva. Las otras dos regiones con un porcentaje importante eran Canama y Malpica."

62 Según el Digesto, los barcos de mayores dimensiones podrían transportar hasta 50.000 modios, que son 340 toneladas, o 10.000 ánforas de vino, cuyo peso alcanza las 500 toneladas (Dig. 50.5.3). 
pues una parte importante de esos 30.000 habitantes no sería consumidora de este producto propio de la dieta mediterránea, al menos durante el tiempo inmediatamente posterior a la conquista; de otro lado, las proporciones de consumo no tenían que ser necesariamente las mismas.

\section{Conclusiones}

Una vez realizada la comparación del material de un lugar y otro, llegamos a las conclusiones siguientes:

1. Los sellos de un punto militar (como Mogontiacum) y civil (como Londinium) no difieren esencialmente, por lo que podríamos deducir que el abastecimiento de estas dos áreas con distintos caracteres habría tenido un recorrido igual o similar.

2. La procedencia conventual de los sellos es similar en ambos lugares a lo largo de los tres primeros siglos. El de Hispalis es el conventus más representado numéricamente, seguido por los de Astigi y Corduba.

3. Las cantidades de ánforas llegadas a un lugar y a otro debieron de ser distintas a tenor del carácter demográfico (militar y civil) que se supone para estos lugares. El abastecimiento de una población civil como Londinium habría dependido del grado progresivo de romanización creciente desde el momento de conquista.

4. En cuanto a los lugares de producción, "La Catria" es el centro más representado, seguido por Alcolea del Río, "Malpica" y Arva, tanto en Mogontiacum como en Londinium.

En definitiva, nos encontramos ante unos materiales semejantes para dos realidades relativamente lejanas y con caracteres sociales distintos, lo cual nos podría hacer pensar que la organización para ese abastecimiento podría haber seguido unos cauces comunes, tanto a nivel administrativo, como en lo referente al uso de rutas de llegada. Esa llegada de materiales se debió de organizar a partir de superconectores o $h u b s^{63}$ - quizá Londinium fuera uno de ellos-desde los que se distribuiría la mercancía a los diferentes puntos secundarios. El mismo caso se daría para Mogontiacum. Propusimos esa idea en el SOMA de Florencia de $2012^{64}$ para el caso de Raetia, donde creemos que Brigantium ejerció de polo redistribuidor del material necesario para la tropa hacia el resto de la provincia y, en especial, para el limes. Ayllón y Pérez toman esta propuesta y la aplican a los materiales del Muro de Adriano poco después, demostrando que nuestra idea puede ser una realidad. ${ }^{65}$ La llegada del aceite hasta el punto final de consumo no iría en perjuicio del uso de una u otra ruta. Como hemos dicho anteriormente, tanto para el caso de Britannia como para el de Germania, nos inclinamos por la atlántica como vía principal de abastecimiento del aceite de oliva

Los superconectores o hubs son lugares principales desde los que se redistribuyen una mercancía o una población.

64 Bermúdez 2013. Sobre la epigrafía anfórica en Raetia, véase también Bermúdez 2014.

65 Ayllón - Pérez 2014. 
bético para el ejército apostado en estas provincias. ${ }^{66}$ Caso futuro de estudio será si esa ruta se mantiene en todo el período altoimperial o si sufre variaciones a lo largo del tiempo.

\section{Anexo}

\begin{tabular}{|c|c|c|c|c|c|}
\hline \multirow[b]{2}{*}{ LH (grupo) 2} & \multirow[b]{2}{*}{ Datación (inferida) } & \multirow[b]{2}{*}{ LP1 } & \multicolumn{3}{|c|}{ Conventus LP1 } \\
\hline & & & Astigi & Corduba & Hispalis \\
\hline \multirow{20}{*}{$\begin{array}{l}\text { Colchester } \\
\text { \& London }\end{array}$} & \multirow{15}{*}{$\begin{array}{l}1-100 \text { p. Chr., } 10-50 \text { p. Chr., } \\
30-50 \text { p. Chr. y } 14 \text { más }\end{array}$} & Villar Tesoro & & & 2 \\
\hline & & Alcolea del Río & & & 9 \\
\hline & & Arva,La Catria,Lora la Vieja & & & 1 \\
\hline & & Azanaque Castillejo & & & 2 \\
\hline & & Berro II & & & 2 \\
\hline & & El Mohino & & 3 & \\
\hline & & Huerta del Río & & & 2 \\
\hline & & La Catria & & & 13 \\
\hline & & La Catria Alta & & & 4 \\
\hline & & La Corregidora & & 1 & \\
\hline & & Las Delicias & 2 & & \\
\hline & & Las Sesenta & & & 3 \\
\hline & & Los Guerras & & & 1 \\
\hline & & Malpica Sur & 1 & & \\
\hline & & Sevilla & & & 7 \\
\hline & \multirow{5}{*}{$\begin{array}{l}\text { 101-200 p.Chr., 138-145 } \\
\text { p. Chr., } 149 \text { p. Chr., } \\
\text { 153-161 p.Chr. y } 9 \text { más. }\end{array}$} & Alcotrista & 1 & & \\
\hline & & La Catria & & & 4 \\
\hline & & Las Sesenta & & & 1 \\
\hline & & Las Valbuenas, Tarancón & 1 & & \\
\hline & & Malpica & 2 & & \\
\hline \multirow{4}{*}{\multicolumn{2}{|c|}{$\begin{array}{l}\text { 161-235 p.Chr.,214 } \\
\text { p.Chr.,201-300 p.Chr., } \\
\text { 193-222 p.Chr., } 224 \text { p.Chr., } \\
\text { 200-223 p.Chr., 201-300 p.Chr. }\end{array}$}} & Arva & & & 1 \\
\hline & & Azanaque Castillejo & & & 1 \\
\hline & & La Catria & & & 2 \\
\hline & & Manuel Nieto & & & 1 \\
\hline & 207-208, 214 p. Chr. & Isla del Castillo,Las Ánimas & 1 & & \\
\hline & 208. 210. 214, 216-217 & La Corregidora & & 1 & \\
\hline
\end{tabular}


LH

\begin{tabular}{|c|c|c|c|c|c|c|}
\hline \multirow{2}{*}{$\begin{array}{l}\text { Conventus } \\
\text { Corduba }\end{array}$} & \multirow{2}{*}{$\begin{array}{l}\text { Cronología } \\
49 \text { p.Chr. }\end{array}$} & \multirow{2}{*}{$\begin{array}{l}\text { LP1 } \\
\text { Barranco del Picacho }\end{array}$} & \multirow{2}{*}{$\begin{array}{l}\text { Familias } \\
\text { CVVA }\end{array}$} & \multicolumn{2}{|c|}{ Colchester London } & Mainz \\
\hline & & & & Abc & & \\
\hline & & Casa de Mingaobez & AGRICOLAE & Abc & & \\
\hline & & Huerta de Belén & SAXFER & $A b c$ & & \\
\hline & & La Corregidora & AELIFVSCIANI & Abc & & \\
\hline & 89 p. Chr. & Barranco del Picacho & CVVA & & & Abc \\
\hline & & Casa de Mingaobez & AGRICOLAE & & & $A b c$ \\
\hline & & Cerro de los Pesebres & SCALENSIA & & & $A b c$ \\
\hline & & & SCALENSIAGEME & & & $\mathrm{Abc}$ \\
\hline & & & SCALENSIACRE & & & Abc \\
\hline & & & SCALFES & & & Abc \\
\hline & & Cortijo del Romero & LVALERIAMETISTI & & & $\mathrm{Abc}$ \\
\hline & & & MAT & & & $A b c$ \\
\hline & & Dehesilla & LFC & & & Abc \\
\hline & & El Mohino & MAELIALEXANDRI & & & $A b c$ \\
\hline & & El Temple & CASTELANI & & & Abc \\
\hline & & & CMARISILVANI & & & Abc \\
\hline & & Huerta & SAXOFER & & & Abc \\
\hline & & de Belén & SAXOFERREO & & & $A b c$ \\
\hline & & & SAXOFERRI & & & $A b c$ \\
\hline & & La Corregidora & MAVRI & & & Abc \\
\hline & & & MCFRIGIDI & & & $A b c$ \\
\hline & & & PMOCVFIGEDO & & & Abc \\
\hline & & Villaseca & CAERARIA & & & $A b c$ \\
\hline & ca. 50 p.Chr. $\& 100-120$ p. Chr. & Casa de Mingaobez & AGRICOLAE & & $A b c$ & \\
\hline & & Casa de Mingaobez Este & MFLAVITITVRI & & Abc & \\
\hline & & Casa del Guarda o Llano & PASSERARIA & & Abc & \\
\hline & & Cerro de los Pesebres & РАH & & $A b c$ & \\
\hline & & & SCALENSIA & & $A b c$ & \\
\hline & & El Mohino & MAELIALEXANDRI & & Abc & \\
\hline & & El Sotillo & FOIAS & & Abc & \\
\hline & & El Temple & CASTELANI & & $A b c$ & \\
\hline & & & CMARISILVANI & & $A b c$ & \\
\hline & & & GALLICI & & Abc & \\
\hline & & & SVRIUS & & $A b c$ & \\
\hline & & Huerta de Belén & FORTUNATI & & Abc & \\
\hline & & La Corregidora & MAVRI & & $A b c$ & \\
\hline & & & PMOCVFIGEDO & & $A b c$ & \\
\hline & & La Umbría de Moratalla & PHOEBUS & & $A b c$ & \\
\hline & & Villaseca & SVAVIS & & & \\
\hline & & & THALI & & $A b c$ & \\
\hline
\end{tabular}

Cantidad de sellos según cronología y lugares de producción indicando el conventus según los dos polos del estudio

\section{Referencias bibliográficas}

Álvarez, J. M. - Nogales, T. - Rodà, I. (eds.), (2014): Actas del XVIII Congreso Internacional de Arqueología Clásica: Centro y periferia en el mundo clásico / Centre and periphery in the ancient world. S. 7. Las vías de comunicación en Grecia y Roma: rutas e infraestructuras. Communication routes in Greece and Rome: routes and infrastructures, Mérida. 
Ayllón, R. - Pérez González, J. (2014): “Oro líquido en los confines del Mundo Romano: la ruta del aceite bético desde las figlinae hasta el Muro de Adriano”, [en] Álvarez et alii (eds.), 2014, 759-763.

Barea Bautista, J. S. - Barea Bautista, J. L. - Solís Siles, J. - Moros Díaz, J. (2008): Figlina Scalensia: Un centro productor de ánforas Dressel 20 de la Bética (=Universitat de Barcelona. Col·lecció Instrumenta 27), Barcelona.

Bermúdez Lorenzo, J. M.

(2013): "Amphorae epigraphy of Raetia", [en] L. Bombardieri - A. D'Agostino G. Guarducci - V. Orsi - S. Valentini (eds.), SOMA 2012. Identity and Connectivity. Proceedings of the 16th Symposium on Mediterranean Archaeology, Florence, Italy, 1-3 March 2012 (=BAR International Series 2581), Oxford, 1053-1056.

(2014): "Rutas de entrada y distribución del aceite de oliva bético en una provincia de frontera: el caso de Raetia”, [en] Álvarez et alii (eds.), 2014, 759-763.

Berni Millet, P.

(2008): Epigrafía anfórica de la Bética. Nuevas formas de análisis (=Universitat de Barcelona. Col·lecció Instrumenta 29), Barcelona.

(2017): "Chapter 8. Amphorae-Epigraphy: Stamps, Graffiti and Tituli Picti from Roman Nijmegen”, [en] Carreras - van den Berg (eds.), 2017, 185-282, 289-343 (https://doi. org/10.2307/j.ctv170x49x.12).

Besnier, A. (1933): “Mogontiacum”, [en] A. Pauly et alii (eds.), Paulys Realencyclopädie der classischen Altertumswissenschaft, Band XV/2, Stuttgart, col. 2422.

Blázquez Martínez, J. Ma - Remesal Rodríguez, J. - Rodríguez Almeida, E. (eds.), (1994): Excavaciones arqueológicas en el Monte Testaccio, Madrid.

Blázquez Martínez, J. Ma - Remesal Rodríguez, J. (eds.)

(1983): Producción y comercio del aceite en la antigüedad. Segundo congreso internacional, Sevilla 24-28 febrero 1982, Madrid.

(1999): Estudios sobre el Monte Testaccio (Roma) I (=Universitat de Barcelona. Col·lecció Instrumenta 6), Barcelona.

(2001): Estudios sobre el Monte Testaccio (Roma) II (=Universitat de Barcelona. Col·lecció Instrumenta 10), Barcelona.

(2003): Estudios sobre el Monte Testaccio (Roma) III (=Universitat de Barcelona. Col·lecció Instrumenta 14), Barcelona.

(2007): Estudios sobre el Monte Testaccio (Roma) IV (=Universitat de Barcelona. Col·lecció Instrumenta 24), Barcelona.

(2010): Estudios sobre el Monte Testaccio (Roma) V (=Universitat de Barcelona. Col·lecció Instrumenta 35), Barcelona.

(2014): Estudios sobre el Monte Testaccio (Roma) VI (=Universitat de Barcelona. Col·lecció Instrumenta 47), Barcelona.

Bonsor, G. E. (1931): The archaeological expedition along the Guadalquivir 1889-1901, New York.

Bourgeon, O. (2012): Las Delicias (Ecija, province de Séville, Espagne): un centre de production d'amphores oléicoles de la vallée du Genil (I ${ }^{e r}$ s.-III ${ }^{e}$ s. ap. J.-C.), Mémoire de Master 1 d'archéologie, Université de Montpellier 3, Lattes-Montpellier (inédito).

Callender, M. H. (1965): Roman amphorae with index of stamps, London.

Carreras, C. - van den Berg, J. (eds.), (2017): Amphorae from the Kops Plateau (Nijmegen). Trade and Supply to the Lower-Rhineland from the Augustan Period to AD 69/70 (=Archaeopress Roman Archaeology 20), Oxford (https://doi.org/10.2307/j. $\operatorname{ctv} 170 \mathrm{x} 49 \mathrm{x})$. 
Carreras Monfort, C. - Funari, P. P. A. (1998): Britannia y el Mediterráneo: estudios sobre el abastecimiento de aceite bético y africano en Britannia (=Universitat de Barcelona. Col·lecció Instrumenta 5), Barcelona.

Chic García, G.

(1975): "Inscripciones de Peñaflor", Habis 6, 357-364.

(1992): "El conjunto alfarero romano de La Catria. Nueva consideración", Minius 1, 107-136. (1995): "Un factor importante de la economía de la Bética: el aceite", Hispania Antiqua 19, 95-128.

Chic García, G. - García Vargas, E. (2004): “Alfares y producciones cerámicas en la provincia de Sevilla. Balance y perspectivas", [en] D. Bernal - L. Lagóstena (eds.), Figlinae Baeticae. Talleres alfareros y producciones cerámicas en la Bética romana (s. II a.C. - VII d.C.) (Cádiz, 12-14 noviembre 2003), (=BAR International Series 1266), Oxford, 279-348.

Ehmig, U.

(1998): "Pinselaufschrift und Stempel auf einer südspanischen Ölamphore aus Mogontiacum", Pyrenae 29, 237-248.

(2003): Der Römischen Amphoren aus Mainz (=Frankfurter Archäologische Schriften 4), Möhnesee.

(2007): Die römischen Amphoren im Umland von Mainz (=Frankfurter Archäologische Schriften 5), Wiesbaden.

Funari, P. P. A. (1996): Dressel 20 Inscriptions from Britain and the Consumption of Spanish Olive Oil. With a Catalogue of Stamps (=BAR British Series 250), Oxford.

Galliou, P. (2004) : Britannia: Histoire et civilisation de la Grande-Bretagne romaine Ier-Ve siècles apr. J.-C., Paris.

Haensch, R. (1997): Capita provinciarum. Statthaltersitze und Provinzialverwaltung in der römischen Kaiserzeit, Mainz.

Hübner, E.

(1873): Inscriptiones Britanniae Latinae, Berolini.

(1899): “Camulodunum", [en] A. Pauly et alii (eds.), Paulys Realencyclopädie der classischen Altertumswissenschaft, Band III/2, Stuttgart, cols. 1448-1449.

Laubenheimer, F. - Marlière, E. (2016): "L'approvisionnement des chefs-lieux de cité dans le nord-ouest de la Gaule à partir du témoignage des amphores", [en] Cl. Besson - O. Blin - Triboulot (eds.), Franges Urbaines confins territoriaux. La Gaule dans l'Empire. Actes du colloque international (Versailles, 29 février - 3 mars 2012), (=Ausonius Éditions. Mémoires 41), Bordeaux.

MacDonald, G. (1927): “Londinium”, [en] A. Pauly et alii (eds.), Paulys Realencyclopädie der classischen Altertumswissenschaft, Band XIII/2, Stuttgart, cols. 1396-1399.

Manacorda, D. - Panella, C. (1993): “Anfore”, [en] W. V. Harris (ed.), The inscribed Economy. Production and Distribution in the Roman Empire in the Light of Instrumentum Domesticum (= Journal of Roman Archaeology supp. ser. VI), Ann Arbor, 55-64.

Marsden, P. (1980): Roman London, London.

Martin-Kilcher, S.

(1983): "Les amphores romaines à huile de Bétique (Dressel 20 et 23) d'Augst (Colonia Augusta Rauricorum) et Kaiseraugst (Castrum Rauracense). Un rapport préliminaire”, [en] Blázquez - Remesal (eds.), 1983, 337-347.

(1987): Die römischen Amphoren aus Augst und Kaiseraugst. Ein Beitrag zur römischen Handels- und Kulturgeschichte, 1. Die südspanischen Ölamphoren (Gruppe 1), (=Forschungen in Augst 7/1), Augst. 
(1991): "Die amphoren von Chur", [en] A. Hochuli-Gysel - A. Siegfried-Weiss - E. Ruoff - V. Schaltenbrand Obrecht (eds.), Chur in römischer Zeit, Bd II. Antiqua, 19, 119-127.

Martin-Kilcher, S. - Schüpbach, S. - Stern, W. B. - Baille, J. (1985): "Keramikanalysen an römischen Olamphoren aus Augst, Kaiseraugst, Avenches und Lausanne-Vidy", Annuaire de la Société Suisse de Préhistoire et d'Archéologie 68, 173-204.

Mateo Corredor, D. (2016): Comercio anfórico y relaciones mercantiles en Hispania Ulterior (s. II a.C. - II d.C.), (=Universitat de Barcelona. Col·lecció Instrumenta 52), Barcelona.

Mauné, S. - García-Vargas, E. - Bourgeon, O. - Carrato, Ch. - García-Dils, S. - Corbeel, S. - Bigot, F. (2014): "L'atelier d'amphores à huile Dr. 20 de Las Delicias à Ecija (Prov. de Séville, Espagne). Résultats de la campagne de fouille 2013 et perspectives", [en] Actes du Congrès International de la SFECAG, Chartres, 29 mai-1 ${ }^{\text {er }}$ juin 2014, Marseille, 365-388.

Merrifield, R. (1983): London. City of the Romans, London.

Panella, C. - Rizzo, G. (2014): Ostia VI. Le terme del nuotatore. Le anfore, Ostia e i commerci mediterranei (=Studi Miscellanei 38), Roma.

Ponsich, M.

(1974): Implantation rurale antique sur le Bas-Guadalquivir I. Séville-Alcalá del RíoLora del Río - Carmona (=Publicaciones de la Casa Velázquez, Sér. Arch. 2), Madrid.

(1979): Implantation rurale antique sur le Bas-Guadalquivir II. La campana-Palma del Río - Posadas (=Publicaciones de la Casa de Velázquez, Sér. Arch. 3), Paris.

(1983): "Le facteur géographique dans les moyens de transport de l'huile de Bétique", [en] Blázquez - Remesal (eds.), 1983, 101-113.

(1987): Implantation rurale antique sur le Bas-Guadalquivir III. Bujalance, Montoro, Andújar (=Publicaciones de la Casa de Velázquez, Sér. Arch. 7), Madrid.

(1991): Implantation rurales antique sur le Bas-Guadalquivir IV. Écija, Dos Hermanas, Los Palacios y Villafranca, Lebrija, Sanlúcar de Barrameda (=Publicaciones de la Casa de Velázquez 33, Sér. Arch. 16), Madrid.

Remesal Rodríguez, J.

(1977-1978): "La economía oleícola bética: nuevas formas de análisis", Archivo Español de Arqueología 50-51, 87-142.

(1979): “Reseña a Dali Colls, Robert Etienne, Robert Lequément, Bernard Liou, Françoise Mayet. L'epave Port-Vendres II et le commerce de la Bétique à l'epoque de Claude, Archaeonautica, 1, Paris (Editions du C.N.R.S.), 1977, pp. 143, fig. 55", Archeologia Classica 31, 379-389.

(1986): La annona militaris y la exportación de aceite bético a Germania. Con un corpus de sellos en ánforas Dressel 20 hallados en Nimega, Colonia, Mainz, Saalburg, Zugmantel y Nida-Heddernheim, Madrid.

(1997): Heeresversorgung und die wirtschaftlichen Beziehungen zwischen der Baetica und Germanien (=Materialh. Arch. Baden-Württemberg 42), Stuttgart.

(2001): "Military supply during wartime", [en] L. De Blois - J. Rich (eds.), The transformation of economic life under the Roman empire. Proceedings of the Second Workshop of the International Network "Impact of Empire" (Roman Empire, c. 200 B. C.-A.D. 476), Nottingham, July 4-7, 2001, Amsterdam, 77-92.

(2008): "Provincial interdependence in the Roman Empire: an explanatory model of Roman economy", [en] P. P. Funari - R. S. Garraffoni - B. Letalien (Eds.), New perspectives on the Ancient World. Modern perceptions, ancient representations (=BAR International Series 1782), Oxford, 155-159. 
(2009): "Heinrich Dressel”, [en] Diccionario Biográfico Español XVI, Madrid, 611-613. (2010): "De Baetica a Germania, consideraciones sobre la ruta y el comercio atlántico en el Imperio Romano", [en] F. Marco Simón - F. Pina Polo - J. Remesal Rodríguez (eds.), Viajeros, peregrinos y aventureros en el mundo antiguo (=Universitat de Barcelona. Col·lecció Instrumenta 36), Barcelona, 147-160.

(2011): La Bética en el concierto del Imperio Romano, Madrid.

Remesal Rodríguez, J. - Berni Millet, P. - Aguilera Martín, A. (2008): “Amphoreninschriften und ihre elektronische Bearbeitung", [en] M. Hainzmann - R. Wedenig, Instrumenta inscripta latina II. Akten des 2. Internationalen Kolloquiums Klagenfurt, 5.-8. Mai 2005, Klagenfurt, 247-264.

Rodríguez Almeida, E. (1977-1978): "Bolli anforari di Monte Testaccio, II”, Bullettino della commissione archeologica comunale di Roma 86, 109-135.

Rougé, J. (1966): Recherches sur l'organisation du commerce maritime en Méditerranée (=École Pratique des Hautes études, VIe Section. Centre de recherches historiques. Ports, routes, trafics, XXL), Paris.

Rubio Campillo, X. - Montanier, J.-M. - Rull, G. - Bermúdez Lorenzo, J. M. - Moros Díaz, J. - Pérez González, J. - Remesal Rodríguez, J. (2018): “The ecology of Roman trade. Reconstructing provincial connectivity with similarity measures", Journal of Archaeological Science 92, 37-47 (https://doi.org/10.1016/j.jas.2018.02.010).

Schäfer, C. (2017): "The debate on the ancient economy as a "battlefield" and the question of transport routes to the Rine region", [en] J. Remesal (ed.), Economía romana. Nuevas perspectivas / The Roman economy. New perspectives (=Universitat de Barcelona. Col·lecció Instrumenta 55), Barcelona, 89-118.

Schimmer, F. (2009): Amphoren aus Cambodunum/Kempten. Ein Beitrag zur Handelsgeschichte der römischen Provinz Raetia, Wiesbaden.

Stylow, A. U. (1988): "Epigrafía romana y paleocristiana de Palma del Río, Córdoba", Ariadna 5, 115-150.

Tchernia, A. (2011): Les romains et le commerce (=Centre Jean Bérard. Études 8), Naples.

Tovar, A. (1974): Iberische Landeskunde, II-1, Baetica, Baden-Baden. 